\title{
KRAS NM_004985.3:C.183A>C
}

National Cancer Institute

\section{Source}

National Cancer Institute. KRAS NM 004985.3:C.183A>C. NCI Thesaurus. Code C98428.

A nucleotide substitution at position 183 of the coding sequence of the KRAS gene where adenine has been mutated to cytosine. 